\title{
Hsp27: A novel therapeutic target for pediatric M4/M5 acute myeloid leukemia
}

\author{
LIANGCHUN YANG $^{1}$, LIZHI CAO ${ }^{1}$, MINGHUA YANG ${ }^{1}$, DAOLIN TANG $^{2}$, \\ RUI KANG ${ }^{1,2}$, XIE MIN ${ }^{1}$, SHAN ZHU ${ }^{1}$ and YAN YU ${ }^{1}$ \\ ${ }^{1}$ Department of Pediatrics, Xiangya Hospital, Central South University, Changsha, Hunan 410008, P.R.China; \\ ${ }^{2}$ Hillman Cancer Center, University of Pittsburgh Cancer Institute, Pittsburgh, PA 15219, USA
}

Received November 26, 2012; Accepted December 28, 2012

DOI: $10.3892 /$ or.2013.2274

\begin{abstract}
Heat shock protein 27 (Hsp27), a member of the heat shock protein (Hsp) family, is critical in the regulation of cancer development, progression and chemotherapy resistance. However, the role of Hsp27 in the pathogenesis of pediatric acute leukemia (AL) remains unknown. In this study, we evaluated the expression levels of Hsp27 in bone marrow samples from 94 children with newly diagnosed acute lymphoblastic leukemia (ALL), acute myeloid leukemia (AML) and 5 leukemia cell lines. Additionally, we transfected a targetspecific siRNA duplex against Hsp27 into leukemia cells, and examined the chemosensitivity and cell apoptosis in the response to antitumor drugs. Hsp27 was abundantly expressed in newly diagnosed AML-M4/M5 bone marrow mononuclear cells (BMMCs) and THP-1, OCI/AML-3 leukemia cell lines. Furthermore, its expression was positively correlated with the clinical status in pediatric M4/M5 subtypes. Knockdown of Hsp27 expression increased the chemosensitivity of leukemia cells and the anticancer drug-induced apoptosis. These results support the theory that Hsp27 plays a contributory role in the pathogenesis of pediatric AML-M4/M5. Therefore, Hsp27 may be exploited as a new target for enhancing the efficacy of chemotherapeutic drugs against leukemia.
\end{abstract}

\section{Introduction}

Acute myeloid leukemia (AML) is a heterogeneous disease with variable clinical outcomes. Despite the fact that the outcome of AML in young patients has substantially improved, only $45-55 \%$ of children with AML are long-term survivors using intensive chemotherapy protocols $(1,2)$. Diverse poor prognostic factors are associated with pediatric AML $(3,4)$.

Correspondence to: Dr Yan Yu, Department of Pediatrics, Xiangya Hospital, Central South University, 110 Xiangya Road, Changsha, Hunan 410008, P.R. China

E-mail: yanglchun@yahoo.cn

Key words: heat shock protein 27, pediatric acute leukemia, M4/M5, chemosensitivity
Studies into new prognostic factors and a more thorough understanding of it will allow for improved therapeutic strategies to enhance overall patient survival.

Hsp27, a member of the small heat shock protein family, has been found to be overexpressed in several types of human carcinomas arising from prostate, breast, gastric, ovarian, bladder and pancreas (5-10). Its expression correlates with TNM stage (11), and is associated with tumor location, poor overall survival and unfavorable prognosis $(12,13)$. Hsp27 may protect tumor cells from chemotherapy and result in aggressively-growing and therapy-resistant tumors $(14,15)$. Knockdown of Hsp27 expression induces apoptosis via Bax activation in a PI3K dependent mechanism in renal epithelial cells and decreases clonogenic survival in HCT116 human colon cancer cells $(16,17)$. Although numerous studies regarding Hsp27 have been performed on malignant cells from a solid tumor, little is known about the role and the expression of Hsp27 in pediatric acute leukemia (AL).

In this study, the expression of Hsp27 in various pediatric AL [acute lymphoblastic leukemia (ALL), M1, M2, M3, M4, M5 and M6] bone marrow mononuclear cells (BMMCs), the relationship between expression of Hsp27 and M4/M5 subtype clinical status and its influence on the chemoresistance and apoptosis of leukemia cells to anticancer drugs, were investigated collectively. We demonstrated that Hsp27 may be a promising therapeutic target for pediatric AML-M4/M5.

\section{Materials and methods}

Patients. Ninety-four children with newly diagnosed AL were studied. Diagnosis was based on May-Grunwald Giemsa stained bone marrow smears and cytochemistry according to the French-American-British (FAB) Group criteria (18). Complete remission (CR), refractory and bone marrow (BM) relapse were defined according to the National Cancer Institute (19). All AML patients were treated by an anthracycline and cytarabine-based induction chemotherapy regimen. One patient received hematopoietic stem cell transplantation (HSCT) after induction therapy. Other patients in CR after induction chemotherapy received post-induction therapy with chemotherapy alone. This study was approved by the research Ethics Committee at the Central South University, and written informed consent was obtained from all patients. 
Cell culture. The human Jurkat T leukemia cells, Burkitt's lymphoma cell Raji, the M2 AML cell line HL-60, the $\mathrm{BCR}-\mathrm{ABL}^{+}$erythroleukemia cell line K562, the acute monocytic leukemia cell line THP-1 (Xiangya School of Medicine Type Culture Collection, China), and the M4 AML cell line OCI/AML-3 (JENNIO Biological Technology, Guangzhou, China) were cultured in RPMI-1640 or DMEM medium with $10 \%$ heat-inactivated fetal bovine serum (FBS), in $5 \% \mathrm{CO}_{2}$ and $95 \%$ air.

Cell separation. For the BMMCs, bone marrow samples were obtained from the patients with AML or ALL. The diagnoses of AML and ALL were based on morphology and flow cytometric analysis of immunophenotype. The BMMCs were isolated by Ficoll density gradient centrifugation $(20,21)$.

Gene transfection and RNAi. Hsp27 siRNA was transfected into cells using X-tremeGENE siRNA Reagent (Roche Applied Science) according to the manufacturer's instructions. In general, the transfection efficiency was $>80 \%$.

Cell viability assay. Cell viability was assessed by the MTT assay. Cells were plated in 96-well flat bottom tissue culture plates at a density of $\sim 5 \times 10^{5}$ cells/well. After the treatment of cells, $20 \mu \mathrm{l}$ of $5 \mathrm{mg} / \mathrm{ml}$ MTT (in PBS) was added to each well, and was continually incubated for $4 \mathrm{~h}$ at $37^{\circ} \mathrm{C}$. The formazan granules obtained in cells were then dissolved in $150 \mu$ l dimethyl sulfoxide (DMSO). The absorbance values were detected at a wavelength of $490 \mathrm{~nm}$ by a 96-well multiscanner autoreader (Thermo Fisher Scientific, USA). The experiments were performed 3 times. Cell viability of MTT $(\%)=(\mathrm{OD}$ of treated cells/OD of control cells $)$ x $100 \%(20,21)$.

Reverse transcription PCR (RT-PCR). Total RNA was isolated from leukemia cells using the TRIzol reagent (Invitrogen, Carlsbad, CA, USA) according to the manufacturer's protocol. RNA concentration and purity were measured with a spectrophotometer at A260 and A260/280, respectively. RNA was reverse-transcribed into cDNA using a Primescript ${ }^{\mathrm{TM}}$ $\mathrm{RT}$ reagent kit (Invitrogen) according to the manufacturer's instructions. The sequences of primers used were: for $\beta$-actin; forward, 5'-TCCTTCCTGGGCATGGAGTC-3' and reverse, 5'-GTAACGCAACTAAGTCATAGTC-3'. For Hsp27; forward, 5'-CCTCTTCGATCAAGCTTCG-3' and reverse, 5'-AGCGGAGCTGAACCACTGA-3'. $\beta$-actin was used as an internal control to evaluate the relative expressions of Hsp27. The conditions for polymerase chain reaction (PCR) to Hsp27 were: denaturation at $94^{\circ} \mathrm{C}$ for $2 \mathrm{~min}$, followed by 30 cycles of $94^{\circ} \mathrm{C}$ for $30 \mathrm{sec}, 56^{\circ} \mathrm{C}$ for $30 \mathrm{sec}\left(\beta\right.$-actin, $50^{\circ} \mathrm{C}$ for $\left.30 \mathrm{sec}\right)$, $72^{\circ} \mathrm{C}$ for $30 \mathrm{sec}$, then by a 5 -min elongation at $72^{\circ} \mathrm{C}$. The PCR products were analyzed with $1.0 \%$ agarose gel electrophoresis and were EB stained, photographed and scanned using Band Leader software for grey scale semi-quantitative analysis.

Western blot analysis. Western blot analysis was used for analyses of expression of Hsp27, cleaved PARP, cleaved caspase-3 and actin. Antibodies against Hsp27, cleaved PARP, cleaved caspase-3 and actin were purchased from Cell Signaling Technology (Danvers, MA, USA). In brief, leukemia cells with different treatments were collected and lysed. The whole cell lysate was separated by $12 \%$ SDS-PAGE and electrophoretically transferred onto polyvinylidene difluoride (PVDF) blotting membrane (Beyotime, Beijing, China). The membrane was blocked with 5\% non-fat dry milk in TBST (50 mM Tris pH 7.5, $100 \mathrm{mM} \mathrm{NaCl}, 0.15 \%$ Tween-20), incubated with the primary antibodies (at various dilutions) for $12 \mathrm{~h}$ at $4^{\circ} \mathrm{C}$, and washed three times with TBST for $10 \mathrm{~min}$. The membranes were then incubated for $12 \mathrm{~h}$ at $4^{\circ} \mathrm{C}$ with different secondary antibodies and detected with ECL reagent (Pierce, Rockford, IL, USA) after three washes with TBST for $10 \mathrm{~min}$. Membranes were exposed to X-ray film and the expressions of the targeted proteins were quantified by detecting the specific band recorded on X-ray film. BandScan 5.0 system was used to quantify and analyze each specific band obtained after western blot analysis.

Apoptosis assays. Apoptosis in cells was assessed using the FITC Annexin V Apoptosis Detection kit [Annexin V-FITC, propidium iodide (PI) solution and Annexin $\mathrm{V}$ binding buffer]. This assay involves staining cells with Annexin V-FITC (a phospholipid-binding protein that binds to disrupted cell membranes) in combination with PI (a vital dye that binds to DNA penetrating into apoptotic cells). Flow cytometric analysis (FACS) was performed to determine the percentage of cells that were undergoing apoptosis (Annexin V+/PI) (21).

Statistical analysis. Data are expressed as the means \pm SEM. Significance of differences between groups was determined by two-tailed Student's t-test or Mann-Whitney U test. $\mathrm{P}<0.05$ was considered to indicate a statistically significant difference.

\section{Results}

Expression of Hsp27 in pediatric AL patients and leukemia cell lines. We studied 94 patients aged 1-15 years with newly diagnosed AL at the Department of Pediatrics of Xiangya Hospital from January 2007 to December 2011. There were 54 males and 40 females. Median age was 5 years (range, 1-13 years). According to FAB classification, 32 patients were identified as ALL, 4 as M1, 22 as M2, 7 as M3, 12 as M4, 15 as M5 and 2 as M6. At time of diagnosis, median white blood cell (WBC) count was $32.3 \times 10^{9} / 1$ (range, 0.6-335.4x10 $/ 1$ ), median hemoglobin level was $67 \mathrm{~g} / \mathrm{l}$ (range, 33-121 g/l), and median platelet count was $29.5 \times 10^{9} / 1$ (range, 6-157 $\times 10^{9} / 1$ ).

Firstly, we determined Hsp27 mRNA and protein expressions in bone marrow samples from 7 newly diagnosed AL samples, including 1 patient with ALL and 6 patients with subtypes of AML (M1, M2, M3, M4, M5 and M6). As shown in Fig. 1A, Hsp27 showed markedly higher expressions in M4/M5 subtypes compared with other types. Additionally, the relative Hsp27 mRNA level was determined from the bone marrow samples of the 94 newly diagnosed patients by RT-PCR analysis. Upregulated Hsp27 expression was also found in BMMCs derived from patients with M4/M5 subtypes. Conversely, these levels were lower in BMMCs derived from ALL, M1, M2, M3 and M6 (Fig. 1B).

Moreover, we determined the levels of Hsp27 in five leukemia cell lines (OCI/AML-3, THP-1, Jurkat, Raji and HL-60) by RT-PCR and western blot analysis. Levels of Hsp27 were high in OCI/AML-3 and THP-1 leukemia cell lines, 
Table I. Characteristics of the 27 AML-M4/M5 patients.

\begin{tabular}{|c|c|c|c|c|c|c|c|}
\hline Subtype & No. & $\begin{array}{l}\text { Age } \\
\text { (years) }\end{array}$ & Gender & $\begin{array}{l}\text { Initial leukocyte } \\
\text { count }\left(\times 10^{9} / 1\right)\end{array}$ & $\begin{array}{l}\text { BM evaluation after } 1 \text { or } 2 \\
\text { induction chemotherapy }\end{array}$ & $\begin{array}{l}\text { Relative Hsp27 } \\
\text { mRNA expression }\end{array}$ & $\begin{array}{l}\text { Survival } \\
\text { outcome }\end{array}$ \\
\hline \multirow[t]{12}{*}{ M4 } & 1 & 5 & $\mathrm{~F}$ & 97.8 & $\mathrm{CR}$ & 0.627 & Deceased (relapse) \\
\hline & 2 & 3 & $\mathrm{~F}$ & 14.2 & $\mathrm{CR}$ & 0.377 & $\mathrm{CR}$ \\
\hline & 3 & 13 & $\mathrm{~F}$ & 23.3 & $\mathrm{CR}$ & 0.355 & Deceased (infection) \\
\hline & 4 & 13 & $\mathrm{~F}$ & 64.7 & IR (BM blasts, 37.5\%) & 0.537 & Deceased (refractory) \\
\hline & 5 & 12 & M & 78.3 & $\mathrm{CR}$ & 0.579 & Deceased (relapse) \\
\hline & 6 & 4 & $\mathrm{~F}$ & 13.5 & $\mathrm{CR}$ & 0.347 & $\mathrm{CR}$ \\
\hline & 7 & 2 & $\mathrm{M}$ & 27.9 & $\mathrm{CR}$ & 0.354 & $\mathrm{CR}$ \\
\hline & 8 & 8 & M & 20.3 & IR (BM blasts, 23\%) & 0.333 & Deceased (refractory) \\
\hline & 9 & 9 & M & 8.2 & $\mathrm{CR}$ & 0.441 & $\mathrm{CR}$ \\
\hline & 10 & 9 & M & 37.3 & $\mathrm{CR}$ & 0.399 & $\mathrm{CR}$ \\
\hline & 11 & 13 & $\mathrm{~F}$ & 33.6 & IR (BM blasts, 15\%) & 0.341 & Deceased (refractory) \\
\hline & 12 & 2 & M & 6.0 & $\mathrm{CR}$ & 0.353 & Deceased (hemorrhage) \\
\hline \multirow[t]{15}{*}{ M5 } & 13 & 12 & $\mathrm{~F}$ & 5.4 & $\mathrm{CR}$ & 0.380 & Deceased (hemorrhage) \\
\hline & 14 & 1 & M & 42.5 & $\mathrm{CR}$ & 0.236 & $\mathrm{CR}$ \\
\hline & 15 & 2 & M & 8.8 & $\mathrm{CR}$ & 0.346 & HSCT \\
\hline & 16 & 11 & $\mathrm{~F}$ & 10.8 & $\mathrm{CR}$ & 0.328 & $\mathrm{CR}$ \\
\hline & 17 & 11 & $\mathrm{~F}$ & 11.1 & $\mathrm{CR}$ & 0.263 & Deceased (refractory) \\
\hline & 18 & 13 & M & 31.5 & IR (BM blasts, $8 \%$ ) & 0.465 & $\mathrm{CR}$ \\
\hline & 19 & 13 & M & 2.2 & $\mathrm{CR}$ & 0 & Deceased (infection) \\
\hline & 20 & 2 & M & 2.4 & $\mathrm{CR}$ & 0.248 & $\mathrm{CR}$ \\
\hline & 21 & 4 & M & 4.6 & $\mathrm{CR}$ & 0.227 & $\mathrm{CR}$ \\
\hline & 22 & 8 & M & 219.7 & $\mathrm{CR}$ & 0.817 & Deceased (relapse) \\
\hline & 23 & 7 & $\mathrm{~F}$ & 145.7 & IR (BM blasts, 55.5\%) & 0.781 & Deceased (refractory) \\
\hline & 24 & 4 & M & 4.2 & $\mathrm{CR}$ & 0.208 & $\mathrm{CR}$ \\
\hline & 25 & 10 & $\mathrm{~F}$ & 132.0 & $\mathrm{CR}$ & 0.680 & Deceased (relapse) \\
\hline & 26 & 10 & M & 86.3 & $\mathrm{CR}$ & 0.578 & Deceased (relapse) \\
\hline & 27 & 4 & $\mathrm{~F}$ & 56.0 & $\mathrm{CR}$ & 0.533 & $\mathrm{CR}$ \\
\hline
\end{tabular}

M4, acute myelomonocytic leukemia; M5, acute monocytic leukemia; F, female; M, male; BM, bone marrow; CR, complete remission

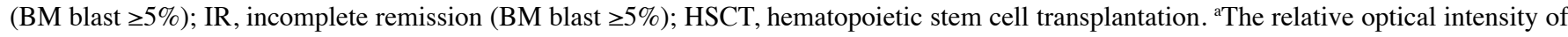
the bands between Hsp27 and $\beta$-actin (Hsp27/ $\beta$-actin).

whereas Hsp27 expression was noticeably lower in Jurkat, Raji and HL-60 cell lines (Fig. 1C). These date suggest that Hsp27 plays a potential contributory role in the pathogenesis of pediatric AML-M4/M5.

Correlation between expression of Hsp27 and clinical status in pediatric M4/M5 subtypes. To further evaluate the clinical relevance between Hsp27 and pediatric AML-M4/M5, we investigated Hsp27 expression in BMMCs obtained from 27 patients, including 12 patients with M4 and 15 patients with M5. The main characteristics of the 27 patients (15 males and 12 females) are presented in Table I. Median age was 9 years (range, 1-13 years). At time of diagnosis, median WBC count was $23.3 \times 10^{9} / 1$ (range, 2.2-219.7x $\left.10^{9} / 1\right)$. Twenty-two of the 27 patients $(81 \%)$ were in complete remission with 1 or 2 induction chemotherapy. Median relative Hsp27 mRNA expression level was 0.355 (range, 0.0-0.817). The survival outcome results revealed that $12 / 27$ patients (44\%) were in complete remission after $\sim 12$ months of chemotherapy. A total of 14 patients died (51\%). Relapse and refractory leukemia were the commonest cause of mortality $(\mathrm{n}=10)$, followed by infection $(n=2)$ and hemorrhage $(n=2)$. All AML patients were treated by an anthracycline and cytarabine-based chemotherapy regimen. One patient received HSCT following induction therapy. The induction chemotherapy regimen information is summarized in Table II.

We firstly detected Hsp27 expression in 27 newly diagnosed M4/M5 patients and 6 normal healthy subjects by RT-PCR analysis (Fig. 2A). The relative Hsp27 mRNA levels are presented in Table I. There was a trend towards a higher incidence of relapse or refractory leukemia in the Hsp27 highexpression patients. There was also a poor prognosis in the 
Table II. Induction chemotherapy regimens of AML-M4/M5 patients.

\section{Regimen}

Regimen 1

M4 (3 patients aged $<10$ years)

M5 (2 patients aged $<9$ years)

Regimen 2

M4 (3 patients aged $>10$ years)

M5 (5 patients aged $>9$ years

and 2 patients aged $<9$ years)

Regimen 3

M4 (2 patients aged $<10$ years)

M5 (1 patient aged $>9$ years)

Regimen 4

M4 (2 patients aged $<10$ years

and 1 patient aged $>10$ years)

M5 (2 patients aged $<9$ years

and 1 patient aged $>9$ years)

Regimen 5

M4 (1 patient aged $<10$ years)

M5 (2 patients aged $<9$ years)
Induction chemotherapy

Daunorubicin $40 \mathrm{mg} / \mathrm{m}^{2} /$ day from Days 1 to 3

Cytarabine $200 \mathrm{mg} / \mathrm{m}^{2} /$ day from Days 1 to 7

Idarubicin $10 \mathrm{mg} / \mathrm{m}^{2} /$ day from Days 1 to 3

Cytarabine $200 \mathrm{mg} / \mathrm{m}^{2} /$ day from Days 1 to 7

Homoharringtonine $3 \mathrm{mg} / \mathrm{m}^{2} /$ day from Days 1 to 7 Daunorubicin $40 \mathrm{mg} / \mathrm{m}^{2} /$ day from Days 1 to 3

Cytarabine $200 \mathrm{mg} / \mathrm{m}^{2} /$ day from Days 1 to 7

Daunorubicin $40 \mathrm{mg} / \mathrm{m}^{2} /$ day from Days 1 to 3

Cytarabine $200 \mathrm{mg} / \mathrm{m}^{2} /$ day from Days 1 to 7

Yituobogan $100 \mathrm{mg} / \mathrm{m}^{2} /$ day from Days 5 to 7

Homoharringtonine $3 \mathrm{mg} / \mathrm{m}^{2} /$ day from Days 1 to 7 Cytarabine $200 \mathrm{mg} / \mathrm{m}^{2} /$ day from Days 1 to 7

Yituobogan $100 \mathrm{mg} / \mathrm{m}^{2} /$ day from Days 1 to 3

AML, acute myeloid leukemia; M4, acute myelomonocytic leukemia; M5, acute monocytic leukemia.

A

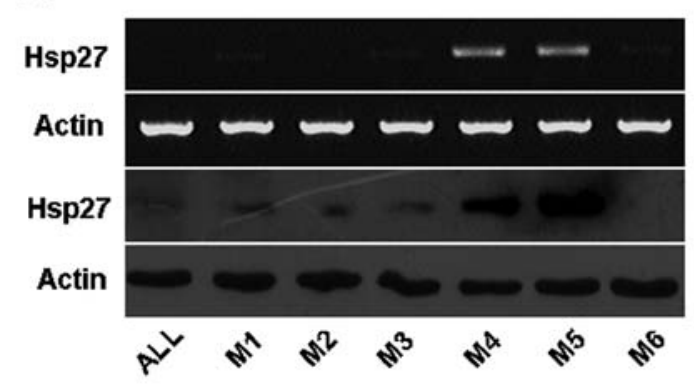

B

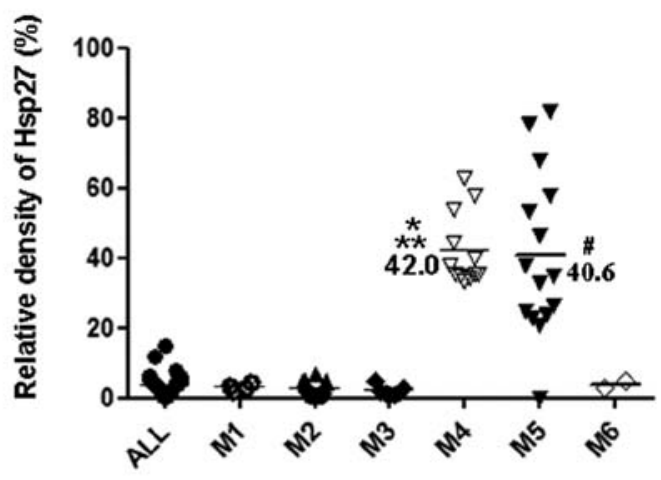

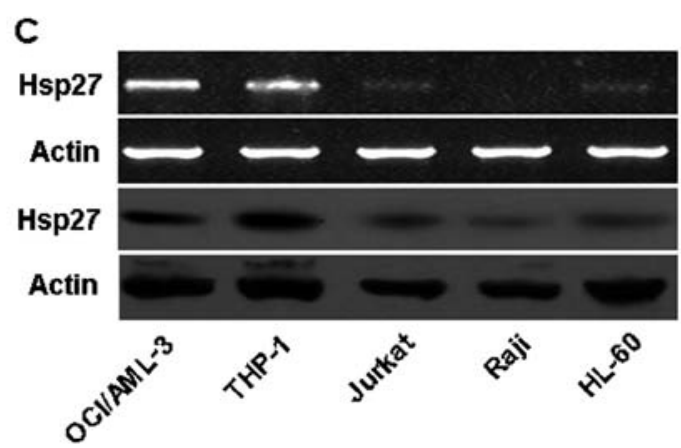

Figure 1. Expression of Hsp27 in pediatric AL patients and leukemia cell lines. (A) Expression of Hsp27 in 7 patients. RT-PCR and western blot analysis of Hsp27 in 7 patients from pediatric ALL and different subtypes of AML as indicated. Actin was used as a loading control. (B) Relative expression levels of Hsp27 in childhood AL. Total mRNA was extracted from patient BMMCs, and Hsp27 level was determined by the relative optical intensity of the bands by RT-PCR analysis. Each dot represents the relative Hsp27 levels in each individual sample. "P<0.05 vs. ALL, M1, M2, M3 and M6; "P<0.05 vs. ALL, M1, M2, M3 and M6; ${ }^{* *} \mathrm{P}>0.05$ vs. M5. (C) Expression of Hsp27 in 5 leukemia cell lines. Total mRNA and protein were extracted from different leukemia cell lines. Hsp27 levels were determined by RT-PCR and western blot analysis. Actin was used as a loading control. ALL, acute lymphoblastic leukemia; M1-M6, the classification of FAB to AML; AML, acute myeloid leukemia. 
Table III. Results of various variables of the patients divided by the BM evaluation.

\begin{tabular}{lccc}
\hline & CR group $(\mathrm{n}=12)$ & Relapse/refractory group $(\mathrm{n}=10)^{\text {P-value }}$ \\
\hline Hsp27 & $0.3505(0.208-0.533)^{\mathrm{b}}$ & $0.5785(0.263-0.817)$ & 0.012 \\
WBCs $\left(\times 10^{9} / 1\right)$ at diagnosis & $13.85(2.4-56)$ & $82.3(11.1-219.7)$ & 0.003 \\
Hb $(\mathrm{g} / \mathrm{l})$ at diagnosis & $59.5(37-83)$ & $65.5(32-82)$ & 0.574 \\
Platelets $\left(\mathrm{x} 10^{9} / \mathrm{l}\right)$ at diagnosis & $26(7-62)$ & $22(5-79)$ & 0.489 \\
Age at diagnosis (years) & $4(1-13)$ & $10(5-13)$ & 0.016 \\
\hline
\end{tabular}

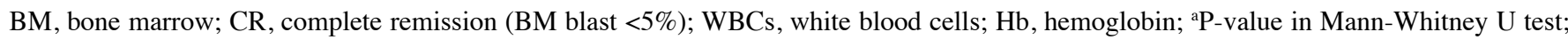
${ }^{\mathrm{b}}$ values shown are the median (minimum-maximum).
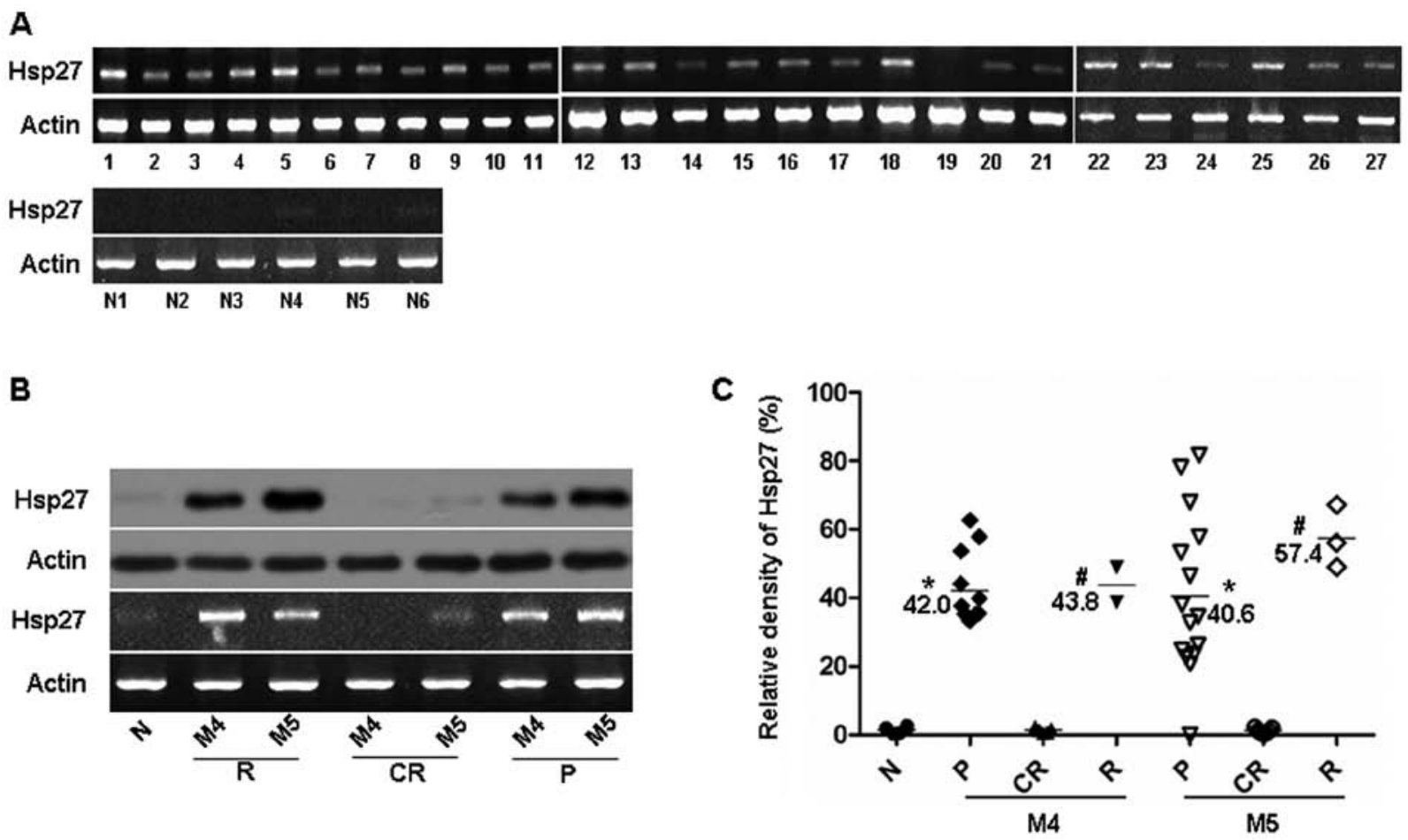

Figure 2. Correlation between expression of Hsp27 and clinical status in pediatric M4/M5 subtypes. (A) Expression of Hsp27 at mRNA level in different samples. Total mRNA was extracted from the BMMCs of 27 patient and 6 normal healthy subjects, and Hsp27 level was determined by RT-PCR analysis. Each patient number corresponds to that shown in Table I. Actin was used as a loading control. (B) Expression of Hsp27 in two patients with different clinical status. Total mRNA and protein from 2 patients were extracted from patient BMMCs, and Hsp27 levels in different clinical status (primary, complete remission and relapse) were determined by RT-PCR and western blot analysis. Actin was used as a loading control. (C) Relative expression levels of Hsp27 in childhood M4/M5 patients. Total mRNA was extracted from BMMCs of normal healthy subjects or patients, and Hsp27 level was determined by the relative optical intensity of the bands by RT-PCR. Each dot represents relative $\mathrm{Hsp} 27$ level in each individual sample. ${ }^{*} \mathrm{P}<0.05$ vs. N; ${ }^{*} \mathrm{P}<0.05$ vs. CR. N, normal healthy subject; $\mathrm{P}$, primary; $\mathrm{CR}$, complete remission; $\mathrm{R}$, relapse.

patients with high WBC and older age at diagnosis (Table III). Moreover, we investigated the expression level of Hsp27 by RT-PCR and western blot analysis in BMMCs obtained from 2 patients with relapse at different clinical status, including 1 patient with M4 and 1 patient with M5. High expression levels of Hsp27 were found in BMMCs derived from patients with primary and relapse leukemia compared with the patients with complete remission, or the normal healthy subject (1 patient) (Fig. 2B).

Furthermore, we investigated the relative Hsp27 mRNA expression levels in the 27 pediatric M4/M5 patients at different clinical status. Higher levels of Hsp27 expression were found in BMMCs derived from patients with primary $(n=27)$ and relapse leukemia ( $n=5)$ (Fig. 2C). By contrast, Hsp27 was not detectable in BMMCs derived from patients with complete remission $(n=12)$, or normal healthy subjects $(n=6)$ (Fig. 2C). These data indicate that Hsp27 correlates well with the clinical status in pediatric M4/M5 subtypes.

Knockdown of Hsp27 expression enhances sensitivity of THP-1 cells to chemotherapeutic drugs. Resistance to chemotherapy is a major impediment to the successful treatment of AML. Hsp27 is considered to play a role in the development of cancer and to modulate tumor response to cytotoxic therapy (22). Whether Hsp27 regulates leukemia cell chemosensitivity has yet to be clarified. In this study, we treated 
A
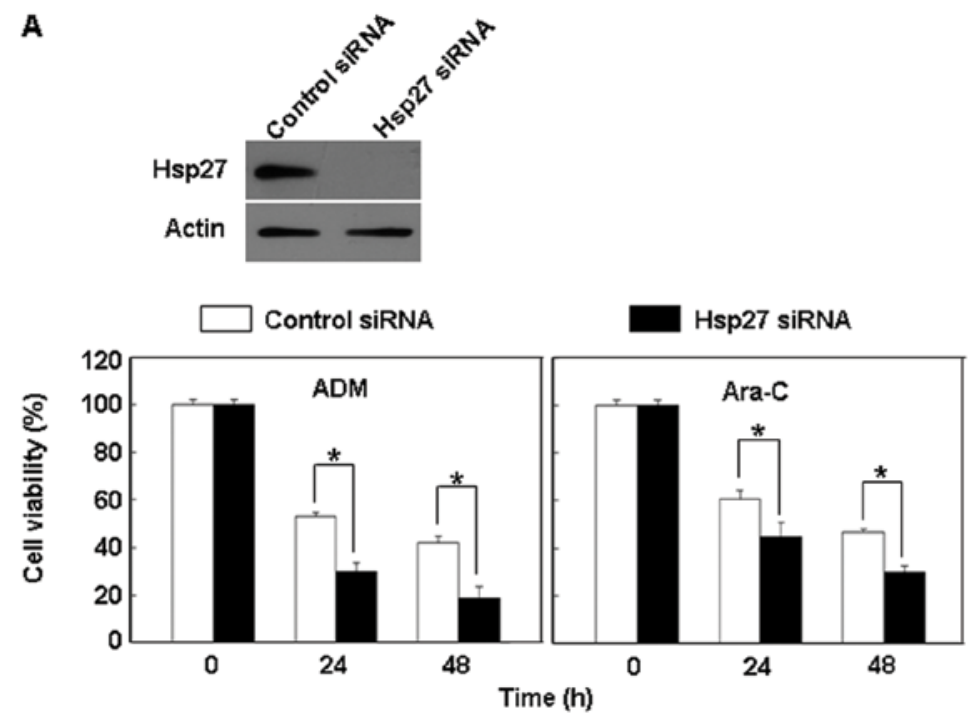

B

$\overline{\mathbf{a}}$

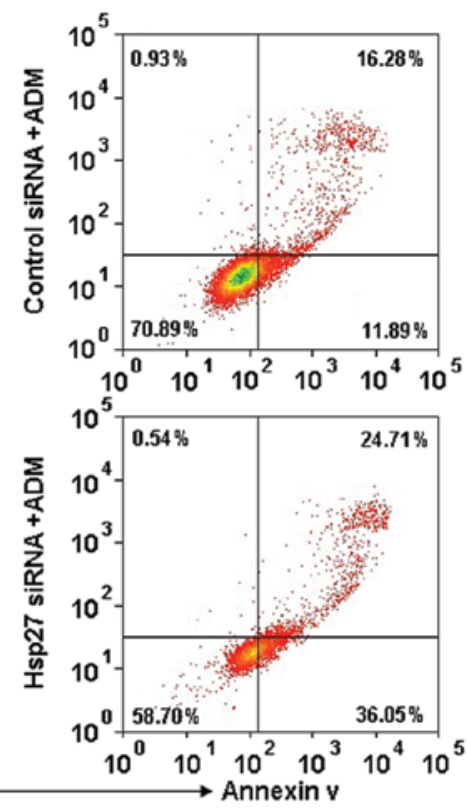

C
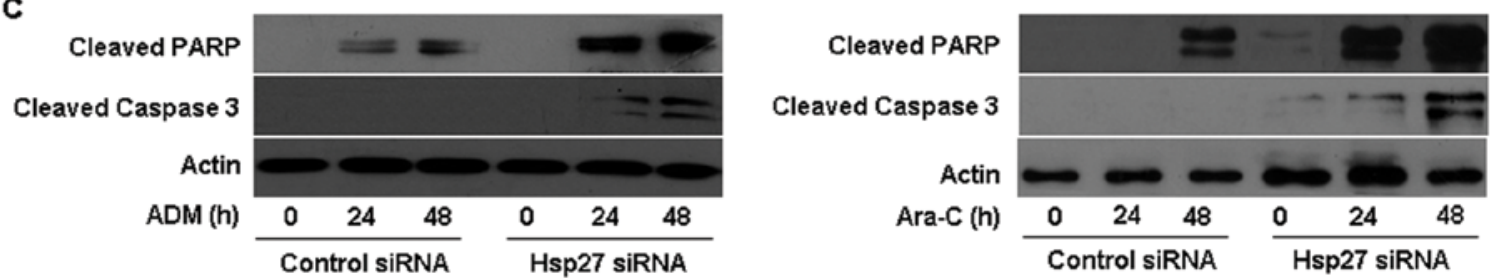

Figure 3. Knockdown of Hsp27 enhances sensitivity of THP-1 cells to chemotherapeutic drugs. (A) Hsp27 knockdown increased the sensitivity of leukemia cells to chemotherapy. Knockdown of Hsp27 by siRNA in THP-1 cells for $48 \mathrm{~h}$ as indicated and then treated with adriamycin (ADM; $1 \mu \mathrm{g} / \mathrm{ml})$ and cytosine arabinoside (Ara-C; $0.2 \mu \mathrm{M}$ ) for 0, 24 and $48 \mathrm{~h}$. Cell viability was assayed by MTT analysis. Knockdown of Hsp27 increased the sensitivity of THP-1 cells to chemotherapy $\left(\mathrm{n}=3 ;{ }^{*} \mathrm{P}<0.05\right)$. (B and C) Hsp27 knockdown increased anticancer drug-induced apoptosis. Knockdown of Hsp27 by siRNA in THP-1 cells for $48 \mathrm{~h}$ as indicated and then treated with ADM $(1 \mu \mathrm{g} / \mathrm{ml})$ and/or Ara-C $(0.2 \mu \mathrm{M})$ for different hours. Cell apoptosis was determined by flow cytometric analysis of Annexin V staining at $48 \mathrm{~h}(\mathrm{~B})$ and western blot analysis of PARP and cleaved caspase-3 for 0, 24 and $48 \mathrm{~h}$ (C). Actin was used as a loading control.

THP-1 cells harboring different status of Hsp27 with several widely used chemotherapeutic drugs in clinic leukemia such as adriamycin (ADM; $1 \mu \mathrm{g} / \mathrm{ml}$ ) and cytosine arabinoside (Ara-C; $0.2 \mu \mathrm{M})(20,21)$. We showed that inactivation of Hsp27 by small interfering RNA (siRNA) significantly enhanced the cytotoxicity of anticancer drugs in THP-1 cells, as compared with the control groups (Fig. 3A). Furthermore, knockdown of Hsp27 expression significantly augmented the anticancer drug-induced apoptosis, as indicated by increases in Annexin V staining and in the amounts of cleaved caspase-3 and PARP (Fig. 3B and C), supporting a potential prosurvival role for Hsp27 in THP-1 leukemia cells exposed to chemotherapy.

\section{Discussion}

Hsp27 is emerging as a promising therapeutic target for the treatment of various types of cancer. High levels of Hsp27 have been observed in a number of cancer cells $(23,24)$, compared to normal cells, in which expression is undetectable or relatively low (25). Moreover, its aberrant expression in cancer is associated with aggressive tumor behavior, increased resistance to chemotherapy, and poor prognosis for the patients (12-14). In our previous investigation, we demonstrated that the prototypical damage-associated molecular pattern molecules (DAMPs), HMGB1 and S100A8, were abundantly expressed in newly diagnosed pediatric AL and contributed to chemotherapy resistance $(20,21)$. Hsp27, another characterized DAMP (26), and the role of Hsp27 in pediatric leukemia has yet to be clearly addressed.

AML represents $20 \%$ of all AL cases in children and adolescents. Clinical outcome of patients with AML remains poor with a long-term survival of $30-50 \%$ in pediatric patients $(27,28)$. The identification of prognostic factors and aberrant signaling pathways in AML is important for the development of new molecular therapies and might improve risk-adapted therapeutic strategies for AML patients. In this study, we found that Hsp27 was abundantly expressed in newly diagnosed pediatric AML-M4/M5 and may be a new target in leukemia therapy.

In childhood AML, MLL gene rearrangements at chromosome band $11 \mathrm{q} 23$ are mainly restricted to the FAB M4 and M5 subtypes, which confer a poor prognosis (29). FAB classification was previously reported to be of prognostic value; M1, M2, M3 and M4Eo are associated with a longer remission duration time than M4 and M5 (30). Also, high WBC count and older age at diagnosis have been established as risk factors for mortality $(31,32)$. In the present study, we found that Hsp27 was abundantly expressed in pediatric AML-M4/M5, but was barely expressed in other types. High expression of Hsp27 correlated well with WBC 
count and age at diagnosis. There was a trend towards a higher incidence of relapse or refractory leukemia in the Hsp27 high-expression pediatric AML-M4/M5 patients. Meanwhile, Hsp27 expression also positively correlated well with clinical status in pediatric AML-M4/M5. We found that Hsp27 expression was significantly higher in the active phase (such as in the primary and relapse phase) and returned to normal in complete remission. This suggested that Hsp27 was associated with an unfavorable prognosis and reduced overall survival in pediatric M4/M5.

Tumor recurrence as a result of resistance to chemotherapeutic drugs remains a formidable problem in managing leukemia patients. Although various mechanisms of drug resistance have thus far been proposed, an exact mechanism remains to be established (33). Several studies demonstrated that the overexpression of Hsp27 appears to be correlated with increased resistance to chemotherapeutic drug-induced apoptosis in cancer cells $(34,35)$. It associates with components of the extrinsic and intrinsic apoptotic pathway, inhibiting the execution of apoptosis and is emerging as an antiapoptotic factor $(36,37)$. In this study, we found that depletion of Hsp27 expression in THP-1 cells by RNA interference increased the chemotherapy sensitivity and the apoptosis of leukemia cells to these anticancer drugs. This clearly suggests a strong effect of Hsp27 on chemoresistance of THP-1 leukemia cells.

In conclusion, in the present study we showed that Hsp27 was overexpressed in pediatric AML-M4/M5, and functioned as an unfavorable prognosis factor. Knockdown of Hsp27 expression by RNA interference increased leukemia cell sensitivity to anti-drug-induced apoptosis. These results support the theory that Hsp27 plays an important role in the tumorigenesis of pediatric AML-M4/M5 and may be exploited as a new target for enhancing the efficacy of chemotherapeutic drugs against leukemia.

\section{Acknowledgements}

This study was supported by grants from The National Natural Science Foundation of China (81270616 to Y.Y. and 31171328 to L.C.).

\section{References}

1. Woods WG: Curing childhood acute myeloid leukemia (AML) at the half-way point: promises to keep and miles to go before we sleep. Pediatr Blood Cancer 46: 565-569, 2006.

2. Creutzig U, Zimmermann M, Reinhardt D, Dworzak M, Stary J and Lehrnbecher T: Early deaths and treatment-related mortality in children undergoing therapy for acute myeloid leukemia: analysis of the multicenter clinical trials AML-BFM93 and AML-BFM 98. J Clin Oncol 22: 4384-4393, 2004

3. Pui CH, Carroll WL, Meshinchi S and Arceci RJ: Biology, risk stratification, and therapy of pediatric acute leukemias: an update. J Clin Oncol 29: 551-565, 2011.

4. Rubnitz JE and Inaba H: Childhood acute myeloid leukemia. $\mathrm{Br}$ J Haematol 159: 259-276, 2012.

5. Rocchi P, Beraldi E, Ettinger S, Fazli L, Vessella RL, Nelson C and Gleave M: Increased Hsp27 after androgen ablation facilitates androgen-independent progression in prostate cancer via signal transducers and activators of transcription 3-mediated suppression of apoptosis. Cancer Res 65: 11083-11093, 2005.

6. Love S and King RJ: A $27 \mathrm{kDa}$ heat shock protein that has anomalous prognostic powers in early and advanced breast cancer. Br J Cancer 69: 743-748, 1994.
7. Huang Q, Ye J, Chen W, et al: Heat shock protein 27 is overexpressed in tumor tissues and increased in sera of patients with gastric adenocarcinoma. Clin Chem Lab Med 48: 263-269, 2010.

8. Langdon SP, Rabiasz GJ, Hirst GL, King RJ, Hawkins RA, Smyth JF and Miller WR: Expression of the heat shock protein Hsp27 in human ovarian cancer. Clin Cancer Res 1: 1603-1609, 1995.

9. Lebret T, Watson RW, Molinié V, O'Neill A, Gabriel C, Fitzpatrick JM and Botto H: Heat shock proteins Hsp27, Hsp60, Hsp70, and Hsp90: expression in bladder carcinoma. Cancer 98: 970-977, 2003.

10. Melle C, Ernst G, Escher N, et al: Protein profiling of microdissected pancreas carcinoma and identification of $\mathrm{Hsp} 27$ as a potential serum marker. Clin Chem 53: 629-635, 2007.

11. Yu Z, Zhi J, Peng X, Zhong X and Xu A: Clinical significance of Hsp27 expression in colorectal cancer. Mol Med Rep 3: 953-958, 2010.

12. Tweedle EM, Khattak I, Ang CW, et al: Low molecular weight heat shock protein HSP27 is a prognostic indicator in rectal cancer but not colon cancer. Gut 59: 1501-1510, 2010.

13. Wang F,Zhang P, Shi C, Yang Y and Qin H: Immunohistochemical detection of Hsp27 and hnRNP K as prognostic and predictive biomarkers for colorectal cancer. Med Oncol 29: 1780-1788, 2012.

14. Yang YX, Xiao ZQ, Chen ZC, et al: Proteome analysis of multidrug resistance in vincristine-resistant human gastric cancer cell line SGC7901/VCR. Proteomics 6: 2009-2021, 2006.

15. Andrieu C, Taieb D, Baylot V, et al: Heat shock protein 27 confers resistance to androgen ablation and chemotherapy in prostate cancer cells through eIF4E. Oncogene 29: 1883-1896, 2010.

16. Havasi A, Li Z, Wang Z, et al: Hsp27 inhibits Bax activation and apoptosis via a phosphatidylinositol 3-kinase-dependent mechanism. J Biol Chem 283: 12305-12313, 2008.

17. O'Callaghan-Sunol C, Gabai VL and Sherman MY: Hsp27 modulates p53 signaling and suppresses cellular senescence. Cancer Res 67: 11779-11788, 2007.

18. Bennett JM, Catovsky D, Daniel MT, Flandrin G, Galton DA, Gralnick HR and Sultan C: Proposed revised criteria for the classification of acute myeloid leukemia: a report of the FrenchAmerican-British Cooperative Group. Ann Intern Med 103: 620-625, 1985.

19. Cheson BD, Cassileth PA, Head DR, et al: Report of the National Cancer Institute sponsored workshop on definitions of diagnosis and response in acute myeloid leukemia: review. J Clin Oncol 8: 813-819, 1990.

20. Yang L, Yu Y, Kang R, et al: Up-regulated autophagy by endogenous high mobility group box-1 promotes chemoresistance in leukemia cells. Leuk Lymphoma 53: 315-322, 2012.

21. Yang L, Yang M, Zhang H, et al: S100A8-targeting siRNA enhances arsenic trioxide-induced myeloid leukemia cell death by downregulating autophagy. Int J Mol Med 29: 65-72, 2012.

22. Garrido C, Ottavi P, Fromentin A, Hammann A, Arrigo AP, Chauffert B and Mehlen P: Hsp27 as a mediator of confluencedependent resistance to cell death induced by anticancer drugs. Cancer Res 57: 2661-2267, 1997.

23. Williams K, Chubb C, Huberman E and Giometti CS: Analysis of differential protein expression in normal and neoplastic human breast epithelial cell lines. Electrophoresis 19: 333-343, 1998.

24. Myung JK, Afjehi-Sadat L, Felizardo-Cabatic M, Slavc I and Lubec G: Expressional patterns of chaperones in ten human tumor cell lines. Proteome Sci 2: 8, 2004.

25. Ciocca DR, Oesterreich S, Chamness GC, McGuire WL and Fuqua SA: Biological and clinical implications of heat shock protein 27,000 (Hsp27): a review. J Natl Cancer Inst 85: 1558-1570, 1993.

26. Chen GY and Nuñez G: Sterile inflammation: sensing and reacting to damage. Nat Rev Immunol 10: 826-837, 2010.

27. Kaspers GJ and Creutzig U: Pediatric acute myeloid leukemia: international progress and future directions. Leukemia 19: 2025-2029, 2005.

28. Molgaard-Hansen L, Glosli H, Jahnukainen K, et al: Quality of health in survivors of childhood acute myeloid leukemia treated with chemotherapy only: A NOPHO-AML study. Pediatr Blood Cancer 57: 1222-1229, 2011.

29. Jo A, Tsukimoto I, Ishii E, Asou N, et al: Age-associated difference in gene expression of paediatric acute myelomonocytic lineage leukaemia (FAB M4 and M5 subtypes) and its correlation with prognosis. Br J Haematol 144: 917-929, 2009. 
30. Ravindranath Y, Chang M, Steuber CP, et al: Pediatric Oncology Group (POG) studies of acute myeloid leukemia (AML): a review of four consecutive childhood AML trials conducted between 1981 and 2000. Leukemia 19: 2101-2116, 2005.

31. Estey E and Dohner H: Acute myeloid leukaemia. Lancet 368 1894-1907, 2006.

32. Dutcher JP, Schiffer CA and Wiernik PH: Hyperleukocytosis in adult acute nonlymphocytic leukemia: impact on remission rate and duration, and survival. J Clin Oncol 5: 1364-1372, 1987.

33. Ross DD: Novel mechanisms of drug resistance in leukemia. Leukemia 14: 467-473, 2000

34. Mori-Iwamoto S, Kuramitsu Y, Ryozawa S, et al: Proteomics finding heat shock protein 27 as a biomarker for resistance of pancreatic cancer cells to gemcitabine. Int J Oncol 31: 1345-1350, 2007.
35. Choi DH, Ha JS, Lee WH, et al: Heat shock protein 27 is associated with irinotecan resistance in human colorectal cancer cells. FEBS Lett 581: 1649-1656, 2007.

36. Lanneau D, Brunet M, Frisan E, Solary E, Fontenay M and Garrido C: Heat shock proteins: essential proteins for apoptosis regulation. J Cel Mol Med 12: 743-761, 2008.

37. Voss OH, Batra S, Kolattukudy SJ, Gonzalez-Mejia ME, Smith JB and Doseff AI: Binding of caspase-3 prodomain to heat shock protein 27 regulates monocyte apoptosis by inhibiting caspase-3 proteolytic activation. J Biol Chem 282: 25088-25099, 2007. 